\title{
Compounds that correct F508del-CFTR trafficking can also correct other protein trafficking diseases: an in vitro study using cell lines
}

Heidi M Sampson ${ }^{1}$, Hung Lam², Pei-Chun Chen³, Donglei Zhang ${ }^{1}$, Cristina Mottillo ${ }^{1}$, Myriam Mirza ${ }^{1}$, Karim Qasim , Alvin Shrier ${ }^{2}$, Show-Ling Shyng ${ }^{3}$, John W Hanrahan ${ }^{2}$ and David Y Thomas ${ }^{1 *}$

\begin{abstract}
Background: Many genetic diseases are due to defects in protein trafficking where the mutant protein is recognized by the quality control systems, retained in the endoplasmic reticulum (ER), and degraded by the proteasome. In many cases, the mutant protein retains function if it can be trafficked to its proper cellular location. We have identified structurally diverse correctors that restore the trafficking and function of the most common mutation causing cystic fibrosis, F508del-CFTR. Most of these correctors do not act directly as ligands of CFTR, but indirectly on other pathways to promote folding and correction. We hypothesize that these proteostasis regulators may also correct other protein trafficking diseases.

Methods: To test our hypothesis, we used stable cell lines or transient transfection to express 2 well-studied trafficking disease mutations in each of 3 different proteins: the arginine-vasopressin receptor 2 (AVPR2, also known as V2R), the human ether-a-go-go-related gene ( $K C N H 2$, also known as $\mathrm{hERG}$ ), and finally the sulfonylurea receptor 1 (ABCC8, also known as SUR1). We treated cells expressing these mutant proteins with 9 structurally diverse F508del-CFTR correctors that function through different cellular mechanisms and assessed whether correction occurred via immunoblotting and functional assays. Results were deemed significantly different from controls by a one-way ANOVA $(p<0.05)$.
\end{abstract}

Results: Here we show that F508del-CFTR correctors RDR1, KM60 and KM57 also correct some mutant alleles of other protein trafficking diseases. We also show that one corrector, the cardiac glycoside ouabain, was found to alter the glycosylation of all mutant alleles tested.

Conclusions: Correctors of F508del-CFTR trafficking might have broader applications to other protein trafficking diseases.

Keywords: Protein trafficking, Corrector, Proteostasis, CFTR, hERG, KCNH2, AVPR2, V2R, ABCC8, SUR1

\section{Background}

Many protein trafficking diseases are caused by mutations that cause temperature sensitive misfolding and can be partially corrected by incubation at low temperature $\left(<30^{\circ} \mathrm{C}\right)$ or treatment with high concentrations of osmolytes such as glycerol, trimethylamine oxide or 4-phenylbutyrate [1-3]. However, most of these are not feasible therapeutic strategies. Small molecule

\footnotetext{
* Correspondence: david.thomas@mcgill.ca

'Department of Biochemistry, McGill University, 3655 Promenade Sir William Osler, Mclntyre Medical Building, Montréal, Québec H3G 1Y6, Canada Full list of author information is available at the end of the article
}

correctors have recently been identified for several protein trafficking diseases including cystic fibrosis (CF) [4-12]. Some of these correctors function as pharmacological chaperones and bind directly to the mutant protein to improve its folding $[10,13]$. Pharmacological chaperones for $\mathrm{CF}$ are predicted to be specific for the cystic fibrosis transmembrane conductance regulator (CFTR) and not correct other mutant proteins unless they share structural similarity with CFTR. Other correctors target cellular pathways and act through proteostasis [14-19]. These proteostasis regulators are predicted to correct diverse protein trafficking diseases. The F508del-CFTR correctors

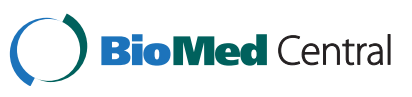


chosen for this study include several structurally distinct compounds that act on different cellular pathways. They include the phosphodiesterase inhibitors KM57 and KM60 [18], poly ADP-ribose polymerase (PARP) inhibitors ABT-888 [14,20] and latonduine [15], the cardiac glycoside ouabain [19], the cyclooxygenase inhibitor glafenine [17], carbamazepine, a sodium channel blocker which promotes proteasomal and autophagic degradation of mutant proteins [21,22], and RDR1, a corrector that we originally reported to act as a pharmacological chaperone [12], but whose mechanism of action remains unclear [23]. We also included the F508del-CFTR pharmacological chaperone VRT-325 [10,13]. Notably, VRT-325 has been reported to correct other mutated proteins besides CFTR [10].

We investigated mutants from a diverse set of wellstudied protein trafficking diseases including the nephrogenic diabetes insipidus mutations V206D and L292P in the arginine-vasopressin receptor 2 (AVPR2, also known as V2R) [24,25], the LQTS2 mutations G601S and F805C in the human ether-a-go-go-related gene $(\mathrm{KCNH} 2$, also known as hERG) $[26,27]$, and finally the persistent hyperinsulinemic hypoglycemia of infancy (PHHI, also known as congenital hyperinsulinism) mutations $\mathrm{A} 116 \mathrm{P}$ and V187D in the sulfonylurea receptor 1 (ABCC8, also known as SUR1) $[10,28,29]$, a component of the $\mathrm{K}_{\mathrm{ATP}}$ channel. All these proteins are localized to the plasma membrane and have one or more glycosylation sites that can be used to monitor their progression through the secretory pathway by immunoblotting, where ER-retained (core-glycosylated) proteins migrate faster than rescued (complex-glycosylated) proteins. Additionally, there is currently no treatment for these diseases that addresses the basic protein trafficking defect.

We show that RDR1 rescues a mutant of the only other ATPase-binding cassette $(\mathrm{ABC})$ protein related to CFTR in our study, SUR1. Additionally, we show that the phosphodiesterase inhibitors KM60 and KM57 rescue the trafficking of a hERG mutant. Finally, we show that ouabain modifies the glycosylation of all mutants tested, albeit without correcting the trafficking of proteins other than CFTR. Our results provide impetus for testing F508del-CFTR correctors on other trafficking disease mutants, which could generate new leads with therapeutic benefit to several rare diseases.

\section{Methods}

\section{Cell lines and constructs}

The GFP-tagged V2R WT clone was generated by sitedirected mutagenesis of plasmid V2R-V206D.GFP, kindly provided by Dr. Peter Deen (NCMLS, The Netherlands), using the primers 5'-CCGTCGCACCTATGTTACCTG GATTGCCC-3' ${ }^{\prime}$ and $5^{\prime}$-GGGCAATCCAGGTAACATAG GTGCGACGG-3'. HA-FLAG-tagged V2R WT and HA- tagged V2R L292P in pcDps, kindly provided by Dr. Torsten Schöneberg (University of Leipzig, Germany), were sub-cloned into pcDNA3.1 using BglII and SpeI sites in pcDps and $B a m H I$ and $X b a I$ sites in pcDNA3.1 (WT) or BglII and XhoI sites (L292P). HEK cells stably expressing HA-tagged hERG G601S [30] were kindly provided by Dr. Eckhard Ficker (Case Western Reserve University, U.S.A.). HA-tagged hERG F805C mutant and WT plasmids have been described previously [31]. FLAG-tagged hamster SUR1 WT, A116P and V187D mutants and rat Kir6.2 plasmids have been described previously [32].

\section{Transfection and compound treatment}

HeLa cells were seeded at a density of $8.0 \times 10^{\wedge} 6$ cells/ flask and transiently transfected with $18 \mu \mathrm{g}$ of plasmid and $63 \mu \mathrm{l}$ of Fugene HD overnight. The following day, the cells were trypsinized and seeded into 6-well plates at $1.0-1.5 \times 10^{\wedge} 6$ cells/well. The following day, the cells were treated with compounds or vehicle at a final DMSO concentration of $0.1 \%$ for 24 h. HEK cells stably expressing 3HA-hERG G601S were seeded in 6-well dishes as above and treated with compounds for $48 \mathrm{~h}$.

\section{Immunoblotting}

Cells were harvested in RIPA buffer $[150 \mathrm{mM} \mathrm{NaCl}$, $20 \mathrm{mM}$ Tris, $0.01 \%$ SDS, $0.08 \%$ sodium deoxycholate, $1 \%$ Triton-X-100, pH 8.0 with protease inhibitors (Roche)]. Equal amounts of protein were separated by SDS-PAGE and transferred onto nitrocellulose. Blots were blocked in PBST $(137 \mathrm{mM} \mathrm{NaCl}, 2.68 \mathrm{mM} \mathrm{KCl}, 9.31 \mathrm{mM}$ $\mathrm{Na}_{2} \mathrm{HPO}_{4}, 2.45 \mathrm{mM} \mathrm{KH} \mathrm{PO}_{4}, \mathrm{pH} 7.4$, containing $0.1 \%$ Tween-20) containing 5\% skim milk and probed with appropriate primary antibodies (rabbit anti-hERG, Calbiochem; SUR1: mouse anti-FLAG M2, Sigma; V2R V206D: mouse anti-GFP, Roche; V2R L292P: mouse anti-HA, Covance). The blots were washed in PBST and probed with HRP-conjugated secondary antibodies. Chemiluminescent substrates were added and the blots were exposed to film.

\section{Densitometry}

The relative levels of each HERG glycoform for selected treatments were estimated by densitometry using Photoshop (Adobe Inc.). The values reported are expressed as means $+/-\mathrm{SD}(\mathrm{n}=3)$.

\section{Patch clamping (hERG G601S)}

Whole-cell currents were recorded from HEK hERG G601S cells after $48 \mathrm{~h}$ of treatment with compounds. An Alembic VE-2 patch clamp amplifier (Alembic Instruments Inc., Montreal) that provides full series resistance compensation was used to record whole-cell currents. The bath solution contained $137 \mathrm{mM} \mathrm{NaCl}, 4 \mathrm{mM} \mathrm{KCl}$, 


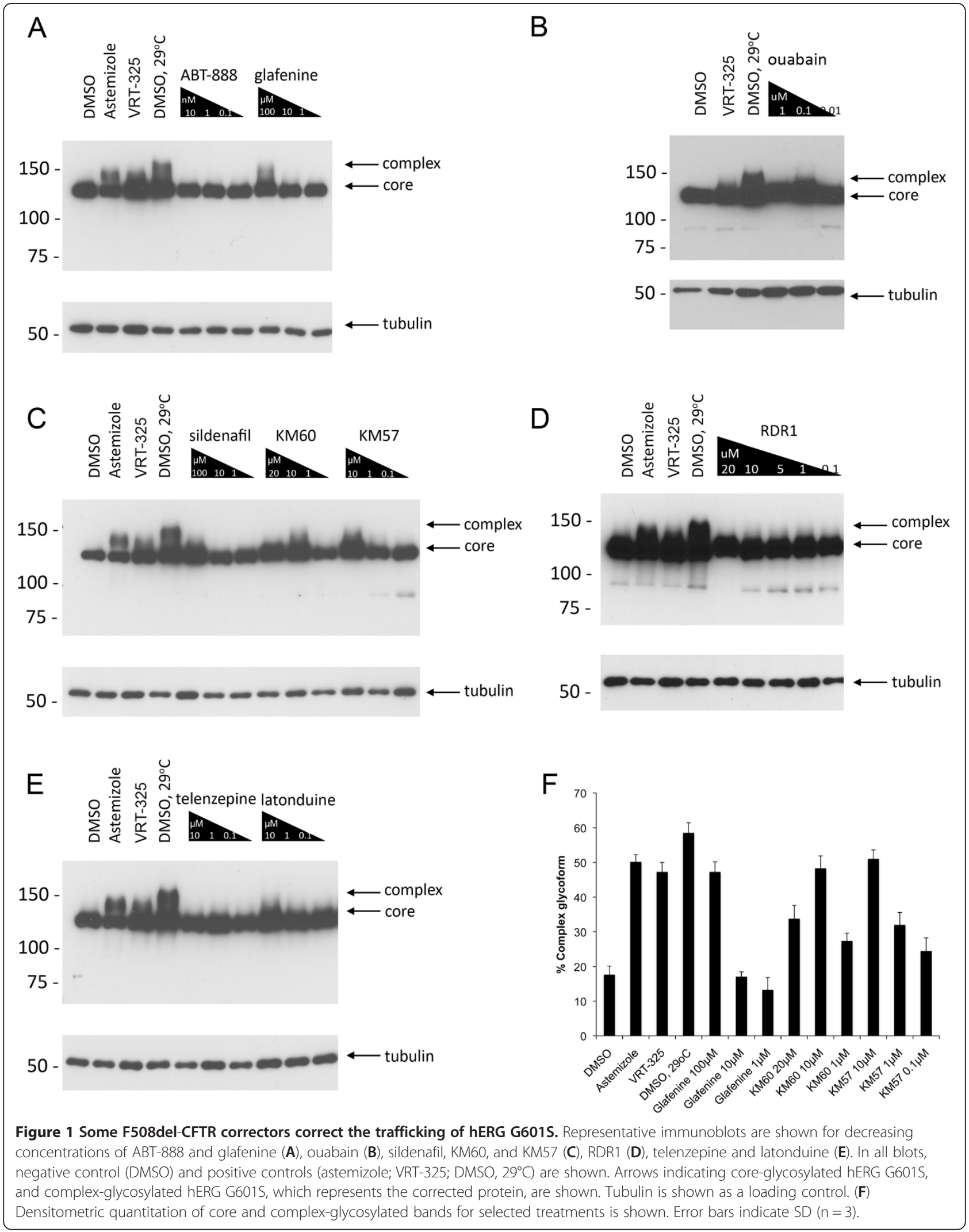




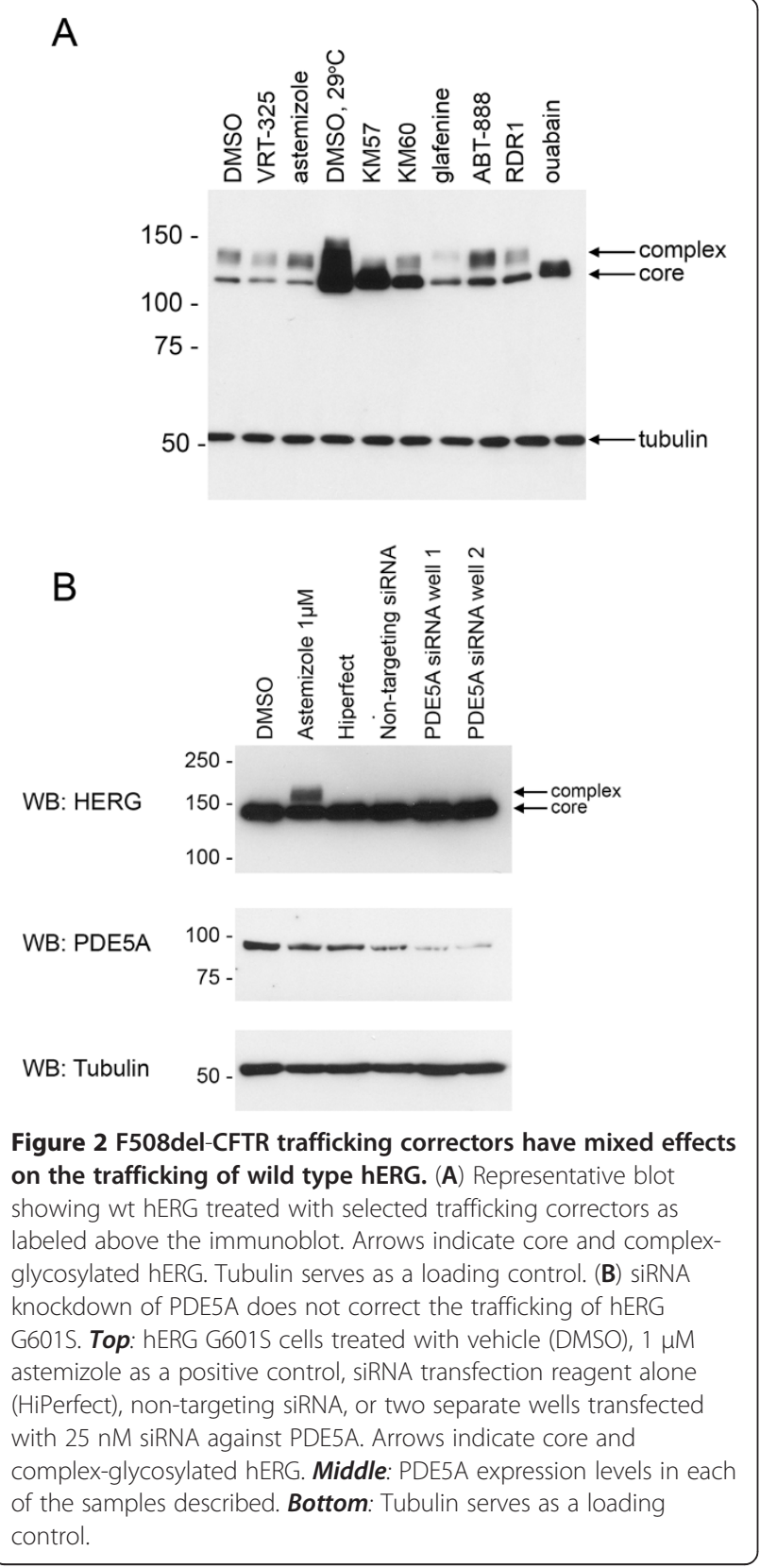

$1.8 \mathrm{mM} \mathrm{CaCl}_{2}, 1 \mathrm{mM} \mathrm{MgCl}, 10 \mathrm{mM}$ glucose and $10 \mathrm{mM}$ HEPES (pH 7.4). Patch pipettes were made from borosilicate glass with a resistance of 3-6 megaohms. Intracellular pipette solution contained $130 \mathrm{mM} \mathrm{KCl}$, $1 \mathrm{mM} \mathrm{MgCl} 2$, $5 \mathrm{mM}$ EGTA, $5 \mathrm{mM} \mathrm{MgATP}$ and $10 \mathrm{mM}$ HEPES (pH 7.2). Cells were held at a potential of $-80 \mathrm{mV}$. hERG tail currents were evoked by $4 \mathrm{~s}$ steps ranging from -60 to $+50 \mathrm{mV}$ in increments of $10 \mathrm{mV}$, with each step followed by a repolarizing step to $-50 \mathrm{mV}$ for $2 \mathrm{~s}$. Data were collected and analyzed with Clampex 8 and Prism software.

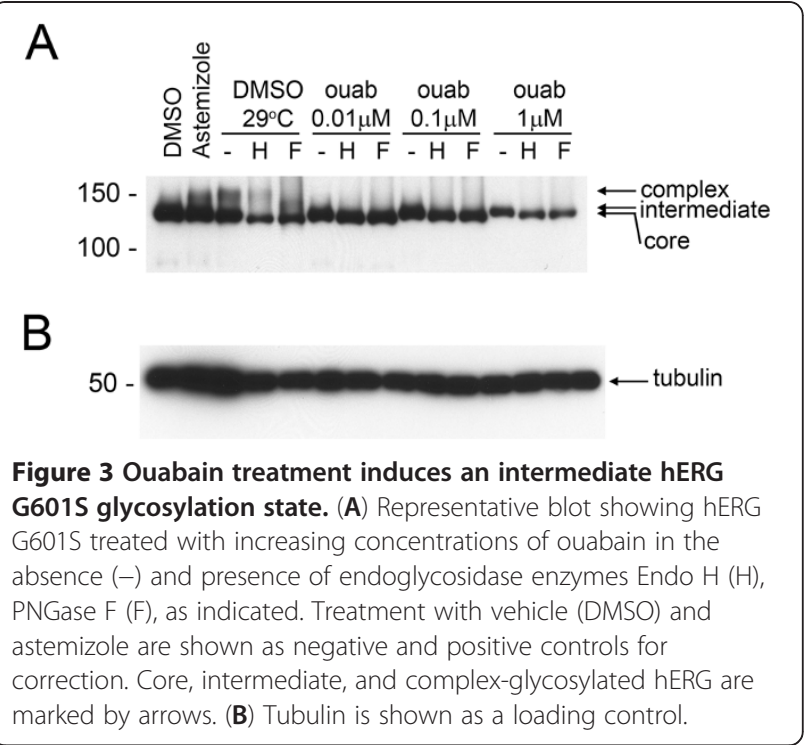

\section{Rubidium efflux (SUR1 mutants)}

COSm6 cells were plated onto 6-well plates and transiently transfected with $0.6 \mu \mathrm{g}$ SUR1 and $0.4 \mu \mathrm{g}$ Kir6.2 plasmids and $3 \mu \mathrm{l}$ Fugene overnight. The following day, the cells were treated with compounds or vehicle for $24 \mathrm{~h}$. Cells were incubated for an additional $12 \mathrm{~h}$ in culture medium containing ${ }^{86} \mathrm{RbCl}(1 \mu \mathrm{Ci} / \mathrm{ml})$; during this period, compounds were present in the first $10 \mathrm{~h}$ followed by a 2-h washout. Before measurement of ${ }^{86} \mathrm{Rb}^{+}$ efflux, cells were incubated for $30 \mathrm{~min}$ at room temperature in Krebs-Ringer solution $(118 \mathrm{mM} \mathrm{NaCl}$,

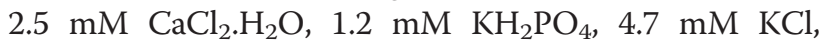
$25 \mathrm{mM} \mathrm{NaHCO}_{3}, 1.2 \mathrm{mM} \mathrm{MgSO}_{4}, 10 \mathrm{mM}$ HEPES, $\mathrm{pH}$ 7.4) with metabolic inhibitors $(2.5 \mu \mathrm{M}$ oligomycin and $1 \mathrm{mM}$ 2-deoxy-D-glucose) to open the channel. At selected time points the solution in the well was collected and fresh solution added. At the end of a 40-min period, the cells were lysed. The ${ }^{86} \mathrm{Rb}^{+}$in the collected solution and the cell lysate was counted. The percentage efflux at each time point was calculated as the cumulative counts in the collected solution divided by the total counts from the solutions and the cell lysate.

\section{Cyclic AMP assays}

Cyclic AMP assays (Sigma-Aldrich) were performed according to the manufacturer's directions. Briefly, cells transfected with V2R plasmids were seeded at $3.0 \times 10^{\wedge} 5$ cells/well in 24-well dishes and treated the following day for $24 \mathrm{~h}$ with compound, in quadruplicate. The following day, the cells were washed with warm PBS and treated with $250 \mu \mathrm{M}$ IBMX for $10 \mathrm{~min}$ to inhibit any phosphodiesterase activity [33]. The medium was aspirated and replaced with either fresh medium containing $0.1 \%$ 


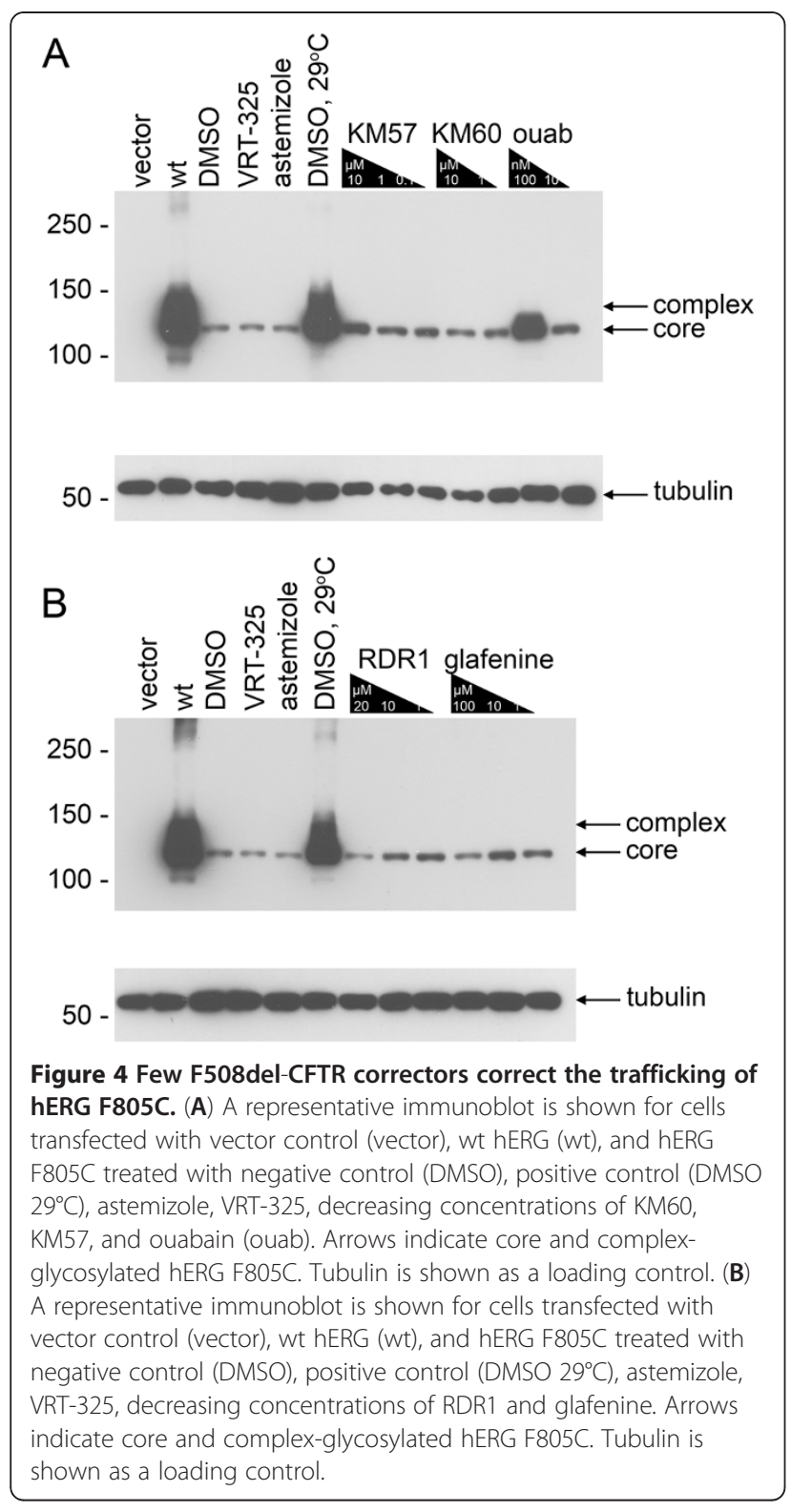

DMSO (unstimulated control, in duplicate) or fresh medium containing $100 \mathrm{nM}$ DDAVP (stimulated, in duplicate) for $10 \mathrm{~min}$ to stimulate V2R at the cell surface [33]. Cells were washed with PBS and lysed in $110 \mu \mathrm{l}$ of $100 \mathrm{mM} \mathrm{HCl}$ at room temperature. Supernatants were collected and centrifuged. $50 \mu \mathrm{l}$ of the supernatant were used in the assay.

\section{Statistical analyses}

Statistical analysis was performed as described in the Figure legends. $P$-values $<0.05$ were considered significant.

\section{Results and discussion}

We tested whether F508del-CFTR correctors could restore hERG G601S trafficking and function. As shown in Figure 1, several correctors including KM57, KM60, glafenine, ouabain, and latonduine modified the glycosylation of this hERG mutant as judged by the appearance of slower-migrating, complex-glycosylated forms of the protein, indicating partial rescue. Treatment with glafenine, KM60 and KM57 resulted in the most prominent complex-glycosylated forms of HERG G601S, while latonduine treatment appeared to yield slightly less rescue. Low temperature, VRT-325 and the hERG channel blocker astemizole served as positive controls $[10,26]$. Interestingly, low temperature treatment produced an additional slower migrating species that was not present in the other positive controls (Figure 1A-E). Treatment with the cardiac glycoside ouabain, a known inhibitor of trafficking of the wild type hERG channel [34] (see also Figure $2 \mathrm{~A}$ ), produced an intermediate glycoform (Figure 1B, Figure 3). Densitometric quantitation of some of the treatments is shown in Figure 1F. We also tested these correctors on the trafficking of the hERG F805C mutant. Unlike hERG G601S, the F805C mutant was only corrected by low temperature and an intermediate glycoform was produced with ouabain treatment (Figure 4). Given that sildenafil, KM60 and KM57 are all phosphodiesterase inhibitors, and KM60 and KM57 were more potent correctors of hERG G601S, we chose to pursue only KM60 and KM57 in our study. To determine if correction resulted in a functional hERG G601S polypeptide, we used patch clamp recording (Figure 5). A short (1 hr) washout of the correctors was necessary to observe an increase in hERG tail currents (Figure 5). Exposure and washout of KM57 (Figure 5C), KM60 (Figure 5D), glafenine (Figure 5E), and astemizole (Figure 5B) all resulted in increased hERG G601S tail currents (Figure 5F). DMSO vehicle (0.1\%) served as a negative control (Figure 5A). Treatment and washout of KM57 resulted in a statistically significant increase in hERG G601S tail currents above the DMSO control (Figure 5F). Since a washout step was necessary to observe tail currents, the mechanism used by these correctors may be through direct binding to, and inhibition of, the mutant channel [35]. Alternatively, KM57 and KM60 may be acting through a proteostasis regulator. To test this hypothesis, we used siRNA knockdown of PDE5A, the purported target of KM60 and KM57. Interestingly, knockdown of PDE5A did not result in an increase in hERG G601S trafficking (Figure 2B). Additionally, treatment of wild type hERG with these correctors reduced the amount of complex-glycosylated mature hERG detected by immunoblotting (Figure 2A). In contrast, low temperature treatment of wild type hERG induced significantly greater amounts of both the core and complex-glycosylated forms of the protein, as would be expected due to the more favorable conditions for protein folding [19]. These results suggest that 


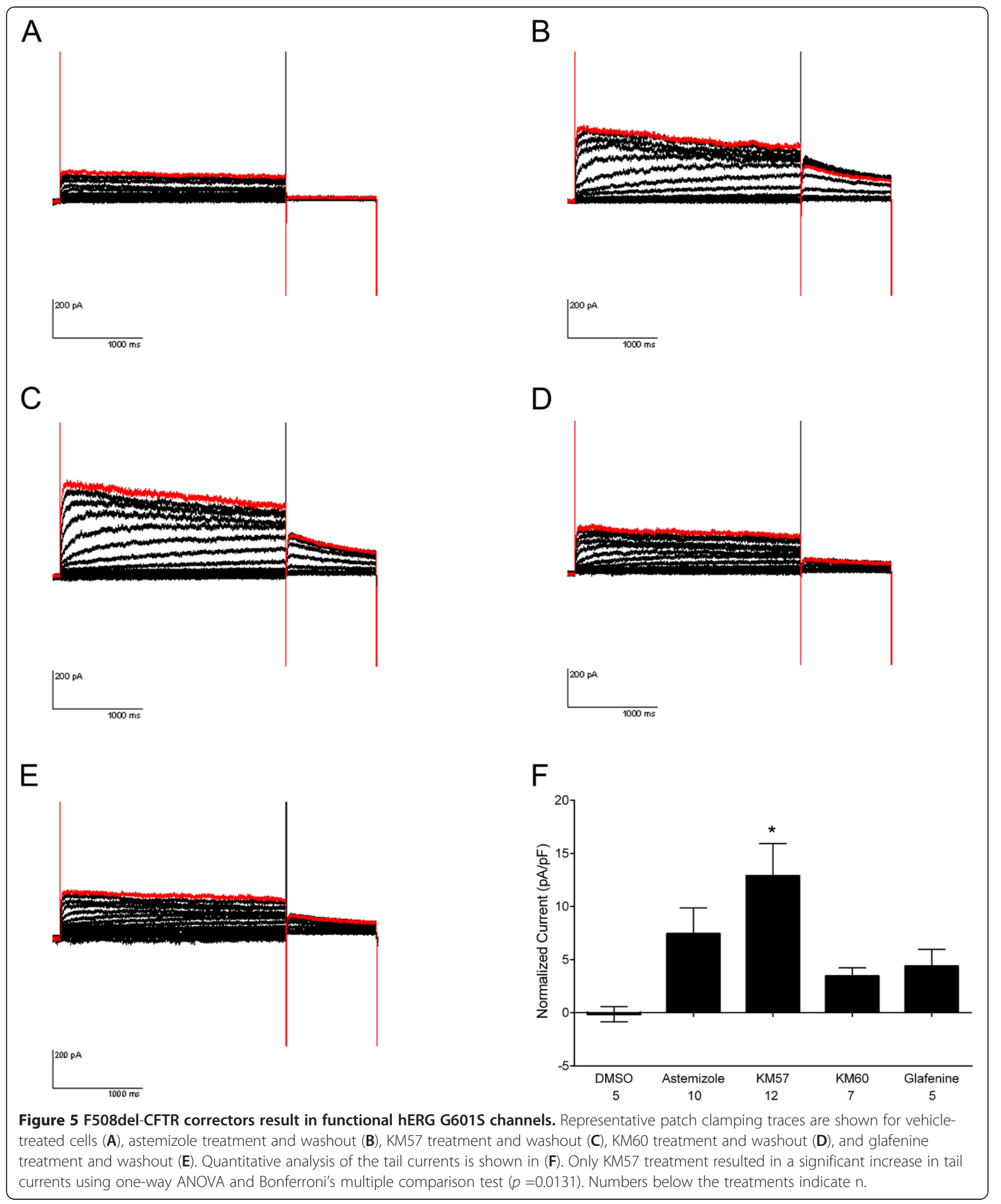




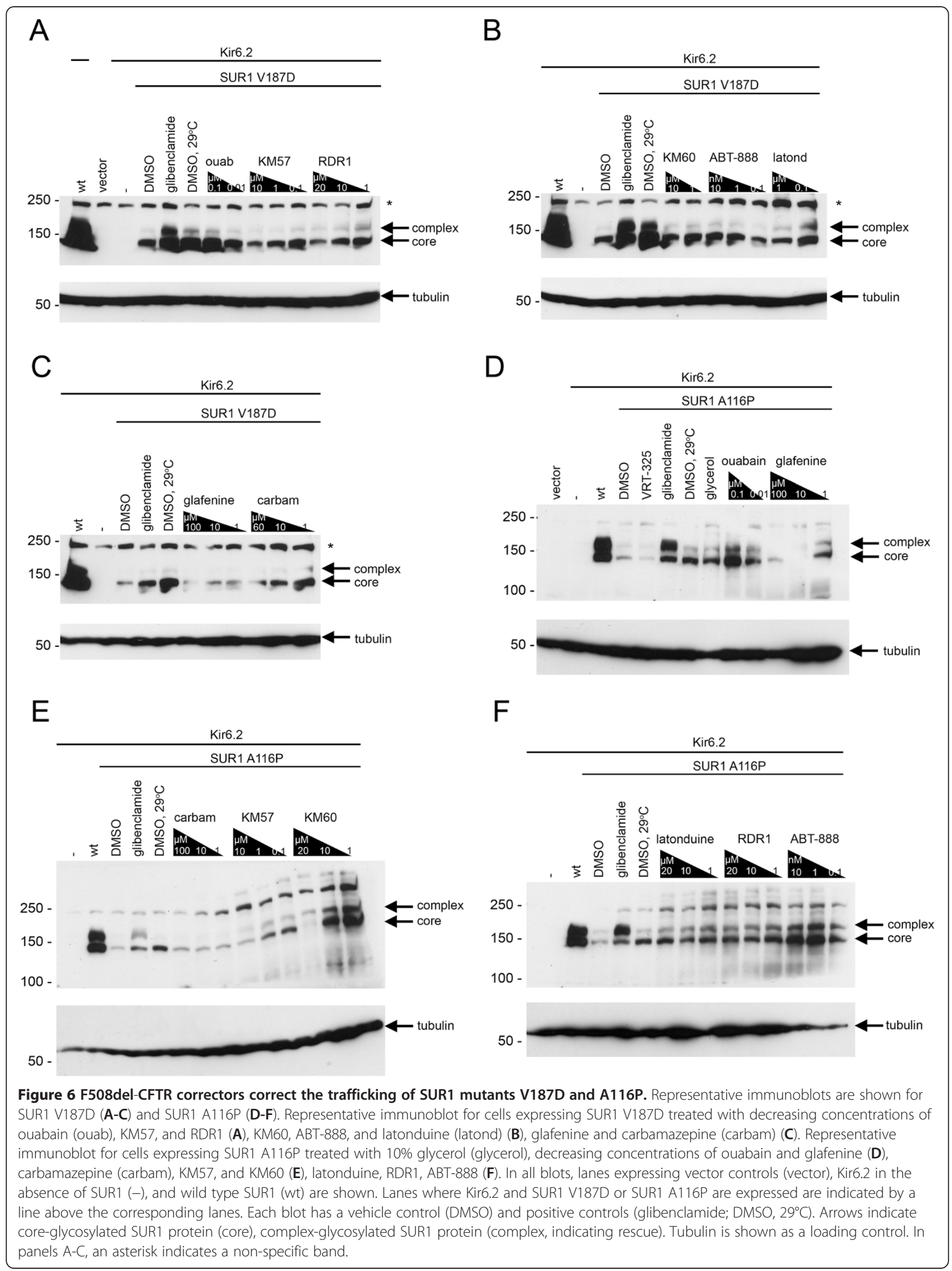



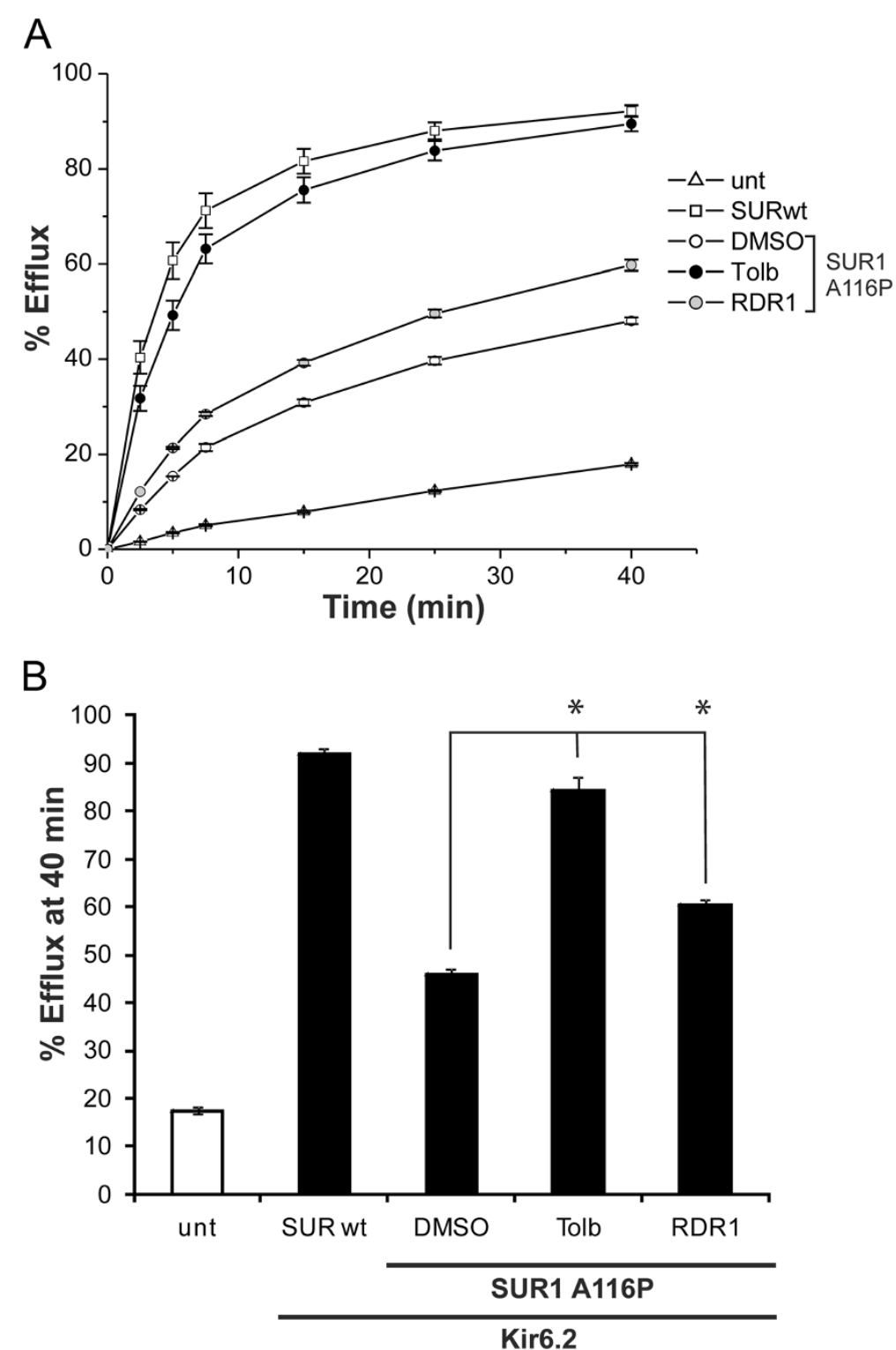

Figure 7 The F508del-CFTR corrector RDR1 improves the function of the SUR1 A116P mutant. (A) Representative ${ }^{86} \mathrm{Rb}^{+}$efflux profiles from

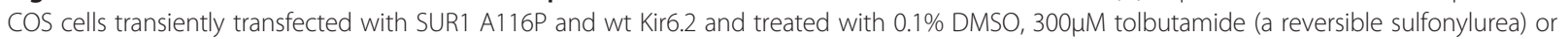
10HM RDR1 as described in the METHODS. Non-transfected cells (unt) and cells transiently transfected with wt SUR1 and Kir6.2 (SURwt) served as controls. Each data point is the average of triplicates performed in the same experiment with the exception of RDR1-treated group (RDR1) in which each data point is the average of six samples. Error bars indicate S.E.M. (B) Comparison of $\%{ }^{86} \mathrm{Rb}^{+}$efflux at the 40 -min time point in cells treated with different compounds. Only RDR1 resulted in significant improvement of channel activity. Each data point is the mean \pm S.E.M. $(n=7)$ from 4 independent experiments; *, $p<0.05$ compared to DMSO treated group by one-way ANOVA and Dunnett's post-hoc test.

KM57 and KM60 may be acting through a proteostasis regulator other than PDE5A to affect hERG trafficking.

We next tested the SUR1 mutants V187D and A116P for correction with F508del-CFTR correctors. Treatment with several correctors yielded the complex-glycosylated form of these mutants, indicating partial rescue (Figure 6). To determine whether correction of the SUR1 mutants leads to functional recovery of $\mathrm{K}_{\mathrm{ATP}}$ channels, we performed ${ }^{86} \mathrm{Rb}^{+}$efflux assays to assess channel activity in intact cells in response to metabolic inhibition (Figure 7). In contrast to cells expressing wild type SUR1 protein, those expressing the SUR1 A116P mutant showed only low levels of channel activity due to loss of surface expression after treatment with the DMSO control. Exposing A116P-expressing cells to the reversible sulfonylurea drug tolbutamide for $>24 \mathrm{~h}$ followed by a washout $2 \mathrm{~h}$ prior to the assay led to almost complete recovery of channel activity, as reported previously [32]. Among the correctors 


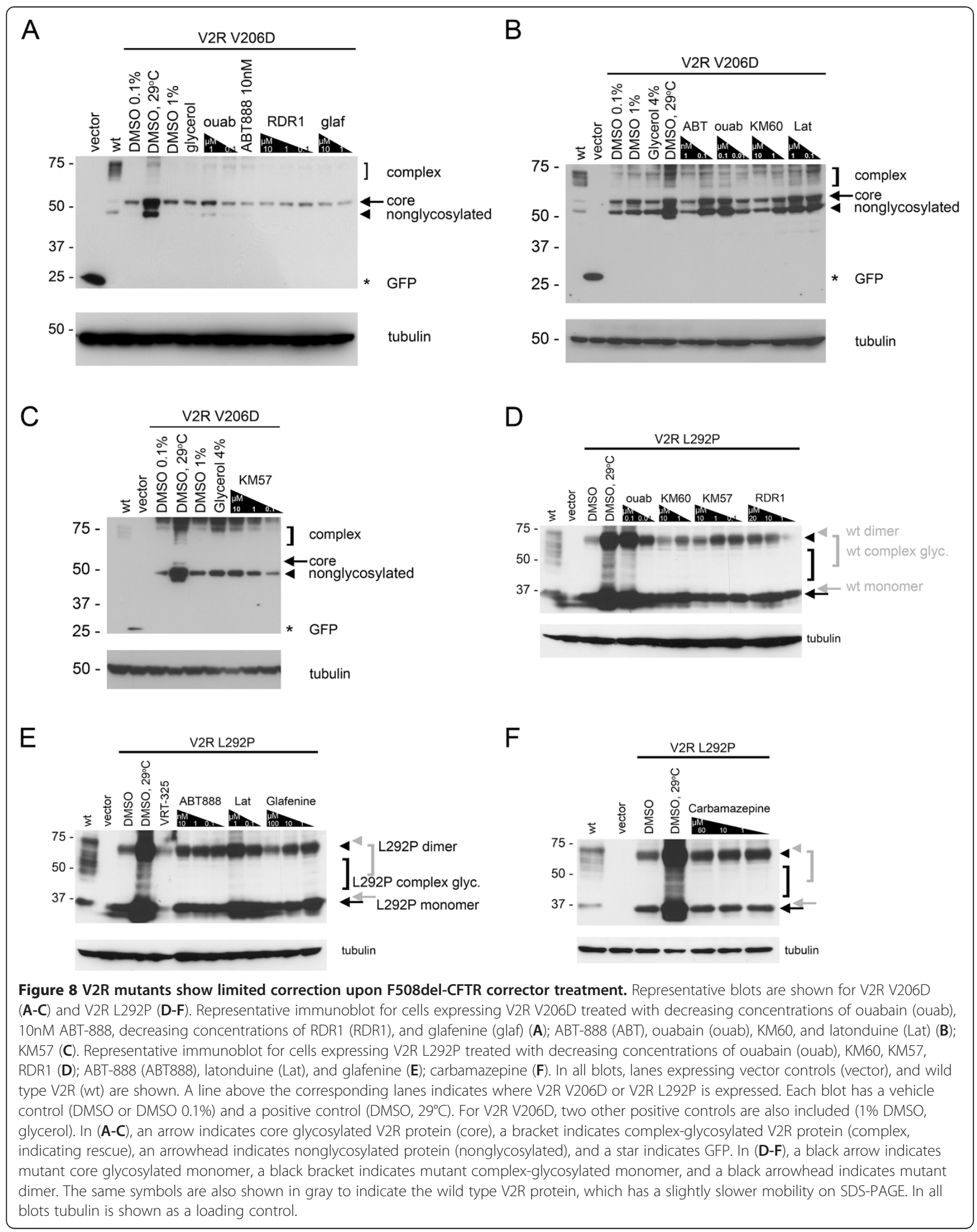



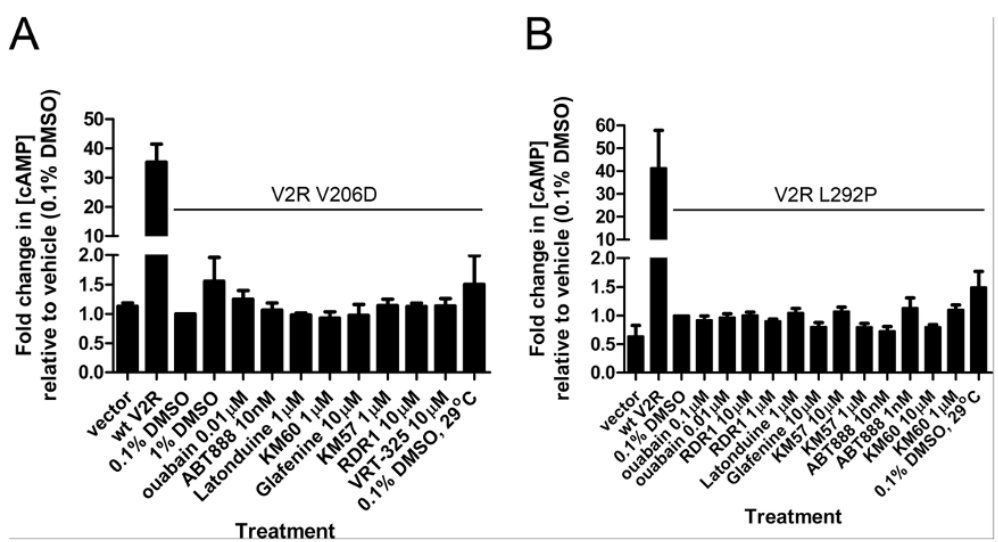

Figure 9 F508del-CFTR correctors do not functionally correct V2R mutants. Cyclic AMP accumulation assays are shown for cells expressing V2R V206D (A) or V2R L292P (B) treated with correctors for 24 h. Data shown are means \pm S.E.M. ( $n=3$ independent experiments). None of the compound treatments were statistically significant from the DMSO control with a one-way ANOVA.

that enhanced the processing of A116P, KM57, KM60 and RDR1 were tested for their effects on functional recovery of the mutant channel. Only RDR1 improved channel function significantly (Figure 7 and data not shown). We previously reported RDR1 as a pharmacological chaperone for F508del-CFTR that binds to and stabilizes the first nucleotide-binding domain (NBD1) against thermal denaturation [12]. However, additional studies since then suggest that RDR1 does not exert its effect through NBD1 [23], although RDR1 may act still as a pharmacological chaperone for F508del-CFTR by affecting other regions of the protein. Interestingly, sulfonylureas correct the trafficking of A116P and V187D mutants by binding to sites outside the affected domain in SUR1, and possibly also with a weak affinity site in Kir6.2 [36]. The mechanism of correction employed by RDR1 may be similar to that proposed for sulfonylureas, perhaps mediated by binding at a different site in SUR1. Alternatively, RDR1 may be acting as a proteostasis regulator through an unidentified protein that exerts its effects on both SUR1 and CFTR.

We also tested these correctors on the V2R mutants L292P and V206D (Figures 8 and 9). Although several correctors increased the trafficking of V2R V206D from ER to the Golgi compartment as evidenced by the appearance of complex-glycosylated forms of the protein (Figure 8A-C), none of them corrected V2R function following stimulation with a vasopressin analog (DDAVP) (Figure 9). The positive controls (1\% DMSO and $29^{\circ} \mathrm{C}$ ) increased cAMP production above the vehicle control with the V2R V206D mutant; however, this difference was

Table 1 F508del-CFTR corrector compounds show distinct profiles of correction for other ER-retained proteins

\begin{tabular}{|c|c|c|c|c|c|c|c|}
\hline Corrector & CFTR F508del & hERG G601S & hERG F805C & SUR1 A116P & SUR1 V187D & V2R L292P & V2R V206D \\
\hline VRT-325 & + & + & - & - & ND & - & ND \\
\hline Glycerol & + & ND & ND & + & ND & ND & $+/-$ \\
\hline $29^{\circ} \mathrm{C}$ & ++ & + & + & + & + & ++ & ++ \\
\hline KM60 & + & + & - & + & + & - & + \\
\hline KM57 & $+/-$ & ++ & - & $+/-$ & - & - & $+/-$ \\
\hline ABT-888 & + & - & ND & + & + & - & + \\
\hline Glafenine & + & + & - & + & - & - & - \\
\hline RDR1 & + & - & - & + & + & - & - \\
\hline Ouabain & + & $+/-^{*}$ & $t^{*}$ & + & + & + & + \\
\hline Carbamazepine & + & - & ND & - & $+/-$ & - & ND \\
\hline Latonduine & + & $+/-$ & - & + & ++ & $+/-$ & + \\
\hline Astemizole & ND & + & - & ND & ND & ND & ND \\
\hline Glibenclamide & ND & ND & ND & ++ & ++ & ND & ND \\
\hline
\end{tabular}

A qualitative assessment of correction as determined by glycosylation status in immunoblotting is shown for each mutation following treatment with a corrector compound, where "-" indicates no correction observed, " $+/-$ " indicates slight correction, " + " and " ++ " indicate more and best correction observed, respectively, and "ND" indicates not determined. Asterisks indicate that an intermediate glycoform was observed, but no correction. Astemizole and glibenclamide were included as positive controls for correction of hERG G601S and SUR1 mutants, respectively. 
not statistically significant (Figure 9A). Cells expressing V2R L292P protein were slightly less amenable to correction by F508del-CFTR correctors than the V206D allele (Figure 8D-F). None of the correctors yielded functional correction upon stimulation (Figure 9B); however, incubation at $29^{\circ} \mathrm{C}$ resulted in approximately 2 -fold more cAMP than at $37^{\circ} \mathrm{C}$ (Figure 9B). This increase was not statistically significant. These results contrast with previously published results using COS cells where low temperature preincubation increased V2R function significantly [25]. The lack of functional correction may be attributed to the use of different cell types, or to the mutant proteins not reaching the cell surface. This latter possibility seems less likely as recent work by Robben et al. shows that intracellular V2R can induce signaling in response to DDAVP stimulation [37].

The results of immunoblotting studies are summarized in Table 1. Only ouabain treatment altered the glycosylation of all mutants. RDR1 correction was the most protein-specific as it only corrected the trafficking of SUR1, the protein structurally related to CFTR in our test set [38]. However, the other correctors did appear to be partially allele-specific. They corrected at least one protein besides F508del-CFTR, but not necessarily both mutant alleles of the same protein.

Among the 9 correctors tested, only the cardiac glycoside ouabain altered the glycosylation of all mutant alleles for these three different ER-retained proteins. The only condition that corrects all mutant alleles is incubation at low temperature. Interestingly, when the transcriptional signatures of ouabain and low temperature are compared, they show significant overlap [19], which may account for the altered glycosylation state of ER-retained mutant proteins. Although the exact mechanism employed by ouabain to elicit trafficking correction of F508del-CFTR has not been elucidated, it is known to inhibit the $\mathrm{Na}+\mathrm{K}+$ ATPase [39]. The inhibition of $\mathrm{Na}+\mathrm{K}+$ ATPase by ouabain leads to intracellular calcium fluctuations and altered glycosylation [40], which, together, could allow ERretained proteins to escape ER-related protein quality control mechanisms. Except for F508del-CFTR, ouabain does not lead to functional correction of the two V2R trafficking mutants that we tested. This discrepancy might be due to the proteins escaping the ER, but not reaching the cell surface where they function. Alternatively, ouabain may not elicit enough correction for a functional response to be detected; suggesting that further optimization of its chemical scaffold or of the optimal dose would be necessary.

\section{Conclusions}

Taken together, the results provide a compelling case for testing novel F508del-CFTR correctors on mutated proteins in other trafficking diseases. Utilizing the hits identified in high throughput screens for correctors of
F508del-CFTR can accelerate the development of correctors for the protein trafficking defect underlying other genetic diseases. A deeper understanding of the targets and mechanisms of action of proteostasis regulators will also be important in the development of these therapeutics.

\section{Competing interests}

The authors declare no competing financial interests.

\section{Authors' contributions}

HMS, HL, PC, AS, S-LS, and DYT designed the experiments. HMS performed the immunoblotting and CAMP assays. HL performed the hERG patch clamping. PC performed the SUR1 rubidium efflux assays. DZ performed the hERG glycosylation enzyme assays. CM, MM and KQ performed critical cloning steps and immunoblotting experiments for V2R HMS, HL, PC, DZ, S-LS, AS JWH and DYT analyzed the data. AS, S-LS, JWH and DYT directed the project. HMS wrote the manuscript with contributions by PC, S-LS, AS, JWH and DYT All authors read and approved the final manuscript.

\section{Acknowledgements}

We thank Dr. Robert J. Bridges (Rosalind Franklin University of Medicine and Science, Chicago) and the CFFT Inc., for providing VRT-325 and Dr. Eckhard Ficker (Case Western Reserve University, Cleveland) for providing the stable HEK293 HERG G601S cell line. We thank Dr. Peter Deen (NCMLS, The Netherlands) and Dr. Torsten Schöneberg (University of Leipzig, Germany) for providing V2R V206D and V2R L292P plasmids, respectively. This work was funded by grants from Cystic Fibrosis Canada, Cystic Fibrosis Foundation Therapeutics, Inc., the Canadian Institutes of Health Research (to DYT, J.W.H. and AS), NIH R01 DK05699 and a grant from the March of Dimes Research Foundation (to S-LS).

\section{Author details}

${ }^{1}$ Department of Biochemistry, McGill University, 3655 Promenade Sir William Osler, Mclntyre Medical Building, Montréal, Québec H3G 1Y6, Canada. ${ }^{2}$ Department of Physiology, McGill University, 3655 Promenade Sir William Osler, Mclntyre Medical Building, Montréal, Québec H3G 1Y6, Canada. ${ }^{3}$ Department of Biochemistry and Molecular Biology, Oregon Health \& Science University, Mail Stop L2243181S.W. Sam Jackson Park Road, Portland, OR 97239-3098, USA.

Received: 21 August 2012 Accepted: 1 January 2013

Published: 14 January 2013

\section{References}

1. Brown CR, Hong-Brown LQ, Biwersi J, Verkman AS, Welch WJ: Chemical chaperones correct the mutant phenotype of the delta F508 cystic fibrosis transmembrane conductance regulator protein. Cell Stress Chaperones 1996, 1:117-125.

2. Denning GM, Anderson MP, Amara JF, Marshall J, Smith AE, Welsh MJ: Processing of mutant cystic fibrosis transmembrane conductance regulator is temperature-sensitive. Nature 1992, 358:761-764.

3. Rubenstein RC, Egan ME, Zeitlin PL: In vitro pharmacologic restoration of CFTR-mediated chloride transport with sodium 4-phenylbutyrate in cystic fibrosis epithelial cells containing delta F508-CFTR. J Clin Invest 1997, 100:2457-2465.

4. Asano N, Ishii S, Kizu H, Ikeda K, Yasuda K, Kato A, Martin OR, Fan JQ: In vitro inhibition and intracellular enhancement of lysosomal alphagalactosidase A activity in Fabry lymphoblasts by 1deoxygalactonojirimycin and its derivatives. Eur J Biochem 2000, 267:4179-4186.

5. Carlile GW, Robert R, Zhang D, Teske KA, Luo Y, Hanrahan JW, Thomas DY: Correctors of protein trafficking defects identified by a novel highthroughput screening assay. Chembiochem 2007, 8:1012-1020.

6. Fan JQ, Ishii S, Asano N, Suzuki Y: Accelerated transport and maturation of lysosomal alpha-galactosidase A in Fabry lymphoblasts by an enzyme inhibitor. Nat Med 1999, 5:112-115.

7. Maegawa GH, Tropak M, Buttner J, Stockley T, Kok F, Clarke JT, Mahuran DJ: Pyrimethamine as a potential pharmacological chaperone for late-onset forms of GM2 gangliosidosis. J Biol Chem 2007, 282:9150-9161. 
8. Sawkar AR, Cheng WC, Beutler E, Wong CH, Balch WE, Kelly JW: Chemical chaperones increase the cellular activity of N370S beta -glucosidase: a therapeutic strategy for Gaucher disease. Proc Natl Acad Sci USA 2002, 99:15428-15433.

9. Tropak MB, Reid SP, Guiral M, Withers SG, Mahuran D: Pharmacological enhancement of beta-hexosaminidase activity in fibroblasts from adult Tay-Sachs and Sandhoff Patients. J Biol Chem 2004, 279:13478-13487.

10. Van Goor F, Straley KS, Cao D, Gonzalez J, Hadida S, Hazlewood A, Joubran J, Knapp T, Makings LR, Miller M, et al: Rescue of DeltaF508-CFTR trafficking and gating in human cystic fibrosis airway primary cultures by small molecules. Am J Physiol Lung Cell Mol Physiol 2006, 290:L1117-L1130.

11. Pedemonte N, Lukacs GL, Du K, Caci E, Zegarra-Moran O, Galietta LJ, Verkman AS: Small-molecule correctors of defective DeltaF508-CFTR cellular processing identified by high-throughput screening. J Clin Invest 2005, 115:2564-2571

12. Sampson HM, Robert R, Liao J, Matthes E, Carlile GW, Hanrahan JW, Thomas DY: Identification of a NBD1-Binding Pharmacological Chaperone that Corrects the Trafficking Defect of F508del-CFTR. Chem Biol 2011 18:231-242

13. Loo TW, Bartlett MC, Clarke DM: Rescue of DeltaF508 and other misprocessed CFTR mutants by a novel quinazoline compound. $\mathrm{Mol}$ Pharm 2005, 2:407-413.

14. Anjos SA, Robert R, Waller DD, Zhang D, Balghi H, Sampson HM, Ciciriello F, Lesimple P, Carlile G, Goepp J, et al: Decreasing Poly(ADP-ribose) Polymerase activity restores DeltaF508 CFTR trafficking. Front Pharmacol 2012, 3:165.

15. Carlile GW, Keyzers RA, Teske KA, Robert R, Williams DE, Linington RG, Gray CA, Anjos SM, Sampson HM, Zhang D, et al: Correction of F508del-CFTR trafficking by the sponge alkaloid latonduine is modulated by interaction with PARP. Chem Biol 2012, 19:1288-1299.

16. Hutt DM, Herman D, Rodrigues AP, Noel S, Pilewski JM, Matteson J, Hoch B, Kellner W, Kelly JW, Schmidt A, et al: Reduced histone deacetylase 7 activity restores function to misfolded CFTR in cystic fibrosis. Nat Chem Biol 2010, 6:25-33.

17. Robert R, Carlile GC, Liao J, Balghi H, Lesimple P, Liu N, Kus B, Rotin D, Wilke $M$, de Jonge $H R$, et al: Correction of the Delta phe508 cystic fibrosis transmembrane conductance regulator trafficking defect by the bioavailable compound glafenine. Mol Pharmacol 2010, 77:922-930.

18. Robert R, Carlile GW, Pavel C, Liu N, Anjos SM, Liao J, Luo Y, Zhang D, Thomas DY, Hanrahan JW: Structural analog of sildenafil identified as a novel corrector of the F508del-CFTR trafficking defect. Mol Pharmacol 2008, 73:478-489.

19. Zhang D, Ciciriello F, Anjos SM, Carissimo A, Liao J, Carlile GW, Balghi H, Robert R, Luini A, Hanrahan JW, Thomas DY: Ouabain mimics low temperature rescue of F508del-CFTR in cystic fibrosis epithelial cells. Front Pharmacol 2012, 3:176.

20. Penning TD, Zhu GD, Gandhi VB, Gong J, Liu X, Shi Y, Klinghofer V, Johnson EF, Donawho CK, Frost DJ, et al: Discovery of the Poly(ADPribose) polymerase (PARP) inhibitor 2-[(R)-2-methylpyrrolidin-2-yl]-1Hbenzimidazole-4-carboxamide (ABT-888) for the treatment of cancer. $J$ Med Chem 2009, 52:514-523.

21. Hidvegi T, Ewing M, Hale P, Dippold C, Beckett C, Kemp C, Maurice N, Mukherjee A, Goldbach C, Watkins S, et al: An autophagy-enhancing drug promotes degradation of mutant alpha1-antitrypsin $\mathrm{Z}$ and reduces hepatic fibrosis. Science 2010, 329:229-232.

22. Rogawski MA, Loscher W: The neurobiology of antiepileptic drugs for the treatment of nonepileptic conditions. Nat Med 2004, 10:685-692.

23. Feng L, Kwok IS-W, Bhatt P, Kaczmatek S, Valdez R, Layer E, Fitzpatrick RJ, Kolodziej AF: RDR-1: Correction and interaction with DeltaF508-NBD1. Pediatr Pulmonol 2012, 47:224-225.

24. Robben JH, Knoers NV, Deen PM: Characterization of vasopressin V2 receptor mutants in nephrogenic diabetes insipidus in a polarized cell model. Am J Physiol Renal Physiol 2005, 289:F265-F272.

25. Tan CM, Nickols HH, Limbird LE: Appropriate polarization following pharmacological rescue of V2 vasopressin receptors encoded by Xlinked nephrogenic diabetes insipidus alleles involves a conformation of the receptor that also attains mature glycosylation. J Biol Chem 2003, 278:35678-35686.

26. Ficker E, Obejero-Paz CA, Zhao S, Brown AM: The binding site for channel blockers that rescue misprocessed human long QT syndrome type 2 ethera-gogo-related gene (HERG) mutations. J Bio/ Chem 2002, 277:4989-4998.
27. Furutani M, Trudeau MC, Hagiwara N, Seki A, Gong Q, Zhou Z, Imamura S, Nagashima H, Kasanuki H, Takao A, et al: Novel mechanism associated with an inherited cardiac arrhythmia: defective protein trafficking by the mutant HERG (G601S) potassium channel. Circulation 1999, 99:2290-2294.

28. Chan KW, Zhang H, Logothetis DE: N-terminal transmembrane domain of the SUR controls trafficking and gating of Kir6 channel subunits. EMBO J 2003, 22:3833-3843.

29. Yang K, Fang K, Fromondi L, Chan KW: Low temperature completely rescues the function of two misfolded K ATP channel disease-mutants. FEBS Lett 2005, 579:4113-4118.

30. Wible BA, Hawryluk P, Ficker E, Kuryshev YA, Kirsch G, Brown AM: HERG-Lite: a novel comprehensive high-throughput screen for drug-induced hERG risk. J Pharmacol Toxicol Methods 2005, 52:136-145.

31. Walker VE, Atanasiu R, Lam H, Shrier A: Co-chaperone FKBP38 promotes HERG trafficking. J Biol Chem 2007, 282:23509-23516.

32. Yan F, Lin CW, Weisiger E, Cartier EA, Taschenberger G, Shyng SL: Sulfonylureas correct trafficking defects of ATP-sensitive potassium channels caused by mutations in the sulfonylurea receptor. J Biol Chem 2004, 279:11096-11105.

33. Robben JH, Sze M, Knoers NV, Deen PM: Functional rescue of vasopressin V2 receptor mutants in MDCK cells by pharmacochaperones: relevance to therapy of nephrogenic diabetes insipidus. Am J Physiol Renal Physiol 2007, 292:F253-F260.

34. Wang L, Wible BA, Wan X, Ficker E: Cardiac glycosides as novel inhibitors of human ether-a-go-go-related gene channel trafficking. J Pharmacol Exp Ther 2007, 320:525-534.

35. Mitcheson JS, Chen J, Lin M, Culberson C, Sanguinetti MC: A structural basis for drug-induced long QT syndrome. Proc Natl Acad Sci USA 2000, 97:12329-12333.

36. Yan FF, Casey J, Shyng SL: Sulfonylureas correct trafficking defects of disease-causing ATP-sensitive potassium channels by binding to the channel complex. J Biol Chem 2006, 281:33403-33413.

37. Robben $\mathrm{JH}$, Kortenoeven ML, Sze M, Yae C, Milligan G, Oorschot VM, Klumperman J, Knoers NV, Deen PM: Intracellular activation of vasopressin V2 receptor mutants in nephrogenic diabetes insipidus by nonpeptide agonists. Proc Natl Acad Sci USA 2009, 106:12195-12200.

38. Campbell JD, Proks P, Lippiat JD, Sansom MS, Ashcroft FM: Identification of a functionally important negatively charged residue within the second catalytic site of the SUR1 nucleotide-binding domains. Diabetes 2004 53(Suppl 3):S123-S127

39. Lingrel JB: The physiological significance of the cardiotonic steroid/ ouabain-binding site of the Na,K-ATPase. Annu Rev Physiol 2010, 72:395-412.

40. Beheshti Zavareh R, Lau KS, Hurren R, Datti A, Ashline DJ, Gronda M, Cheung P, Simpson CD, Liu W, Wasylishen AR, et al: Inhibition of the sodium/potassium ATPase impairs $\mathrm{N}$-glycan expression and function. Cancer Res 2008, 68:6688-6697.

\section{doi:10.1186/1750-1172-8-11}

Cite this article as: Sampson et al: Compounds that correct F508delCFTR trafficking can also correct other protein trafficking diseases: an in vitro study using cell lines. Orphanet Journal of Rare Diseases 2013 8:11.

\section{Submit your next manuscript to BioMed Central and take full advantage of:}

- Convenient online submission

- Thorough peer review

- No space constraints or color figure charges

- Immediate publication on acceptance

- Inclusion in PubMed, CAS, Scopus and Google Scholar

- Research which is freely available for redistribution 